Original Research

\title{
Survey of undergraduates' perceptions of experiential learning in the MPharm programme: The TELL Project
}

\author{
Sabrina A. JACOB D, Anne C. BOYTER ${ }^{D}$. \\ Received (first version): 24-Feb-2020 Accepted: 14-Jun-2020 Published online: 16-Jun-2020
}

\begin{abstract}
Objective: To determine the perception of undergraduate pharmacy students of their experiential learning (EL) placements both in the community and hospital settings.

Methods: A cross-sectional survey was conducted utilizing a six-item online survey consisting of one open-ended and five closedended questions, the latter utilising five-point Likert-type scales ranging from strongly disagree (1) to strongly agree (5). All undergraduate pharmacy students from the School of Pharmacy $(\mathrm{N}=496)$ were included in the study. Survey questions assessed students' perceptions on the effectiveness of the EL, tutors and placements sites, and organisation and structure of the EL. Thematic content analysis was performed on the open-ended comments, where relevant themes were generated.

Results: From the 139 responses (response rate: $28 \%$ ), 121 responses were analysed, and of these, $72.5 \%$ already had part-time jobs in community pharmacies. Close to $85 \%$ felt that their part-time work should contribute to EL hours, which is currently not recognised by the university. Respondents were positive about the effectiveness of EL in developing their professionalism and communication $(M=3.84, S D=1.05)$, clinical $(M=3.42, S D=1.22)$, and technical skills $(M=3.32, S D=1.25)$ Respondents provided favourable feedback about their experience in the hospital as it gave them a real-world exposure to the role of a hospital pharmacist. Community placements were not viewed favourably and this was mainly attributed to the poor experience with tutors whom they felt used them as an extra pair of hands. This was thought to impede their learning experience. They also felt that hospital placements were of insufficient duration, reported by $72.5 \%$ of respondents. Respondents also felt they should be sent to other sites such as primary care for placements.

Conclusions: Tutor-training is key to ensure tutors are aware of the responsibilities and expectations. Similarly, quality assurance measures should be adopted to ensure tutors and placement sites are capable of providing students with an effective placement experience. While placement durations are a concern, the focus should be on the quality of the placement experience, and ensuring there is structure and flexibility. Content changes are also needed to include emerging placement sites such as primary care to prepare students for evolving pharmacist roles in the changing healthcare system.
\end{abstract}

Keywords

Students, Pharmacy; Education, Pharmacy; Pharmacy Residencies; Professionalism; Motivation; Pharmacists; Pharmacy Service, Hospital; Pharmacies; Primary Health Care; Cross-Sectional Studies; Scotland

\section{INTRODUCTION}

Experiential learning (EL) has long been adopted by pharmacy schools worldwide and finds its roots in Kolb's experiential learning theory, which is typically represented in a four-stage cycle of learning (Figure 1). ${ }^{1}$ Through placements at practice sites, and under the guidance of tutors, students are able to transform the experience into knowledge. This is achieved through reflection and the development of new concepts. Students then apply the new skills gained in practice, thereby creating a new experience and a continuation of the cycle. ${ }^{1}$ In the United Kingdom (UK), the term 'tutor' is used to denote a 'registered, practising pharmacist who supervises pharmacy students during placements'. ${ }^{2}$ EL plays a key role in equipping pharmacy students with the necessary skills needed by a pharmacist such as professionalism, clinical, technical, and communication, in an effort to enable them to transition seamlessly into the practice environment. Indeed, studies have found that EL provided students with real-world experiences to help them obtain a more realistic

Sabrina Anne JACOB. BPharm (Hons), MPharm (Clin Pharm), PhD (Clin Pharm). Research associate. Strathclyde Institute of Pharmacy and Biomedical Sciences, University of Strathclyde. Glasgow, Scotland (United Kingdom). sabrina.jacob@strath.ac.uk

Anne C. BOYTER. BSc, MSc, PhD. Director of Teaching \& Deputy

Head of Institute. Strathclyde Institute of Pharmacy and Biomedical

Sciences, University of Strathclyde. Glasgow, Scotland (United

Kingdom). anne.boyter@strath.ac.uk perspective of the role of pharmacists and the healthcare system, increased students' confidence in patient-facing roles such as counselling, and helped reinforce previous learning. ${ }^{3-6}$

Students have, however, reported feeling overwhelmed during their hospital placements. ${ }^{7}$ Students also expressed that there was a disconnect between what is studied at university, and what actually happens in the practice environment - often struggling to apply their knowledge during their placements. ${ }^{7,8}$ As it pertained to assessments, students found reflection activities difficult, and felt journaling was too time consuming. ${ }^{9,10}$ These suggest shortcomings, perhaps in the design and execution of EL.

In the UK, EL is still developing where there are no stipulated placement hours by the General Pharmaceutical Council (GPhC), the regulator of pharmacists. There is only the specification that the amount of EL needs to increase over the years. ${ }^{11}$ As such there is variation between the different universities in terms of placement hours, and the structure and governance of EL. ${ }^{12}$ Funding depends on each university's resources as well as any external funding.

The EL at the School of Pharmacy has been part of the fouryear undergraduate Master of Pharmacy (MPharm) curriculum for over 20 years and focuses predominantly on community and hospital settings (Table 1). At the time of this evaluation, placement sites were volunteered by 


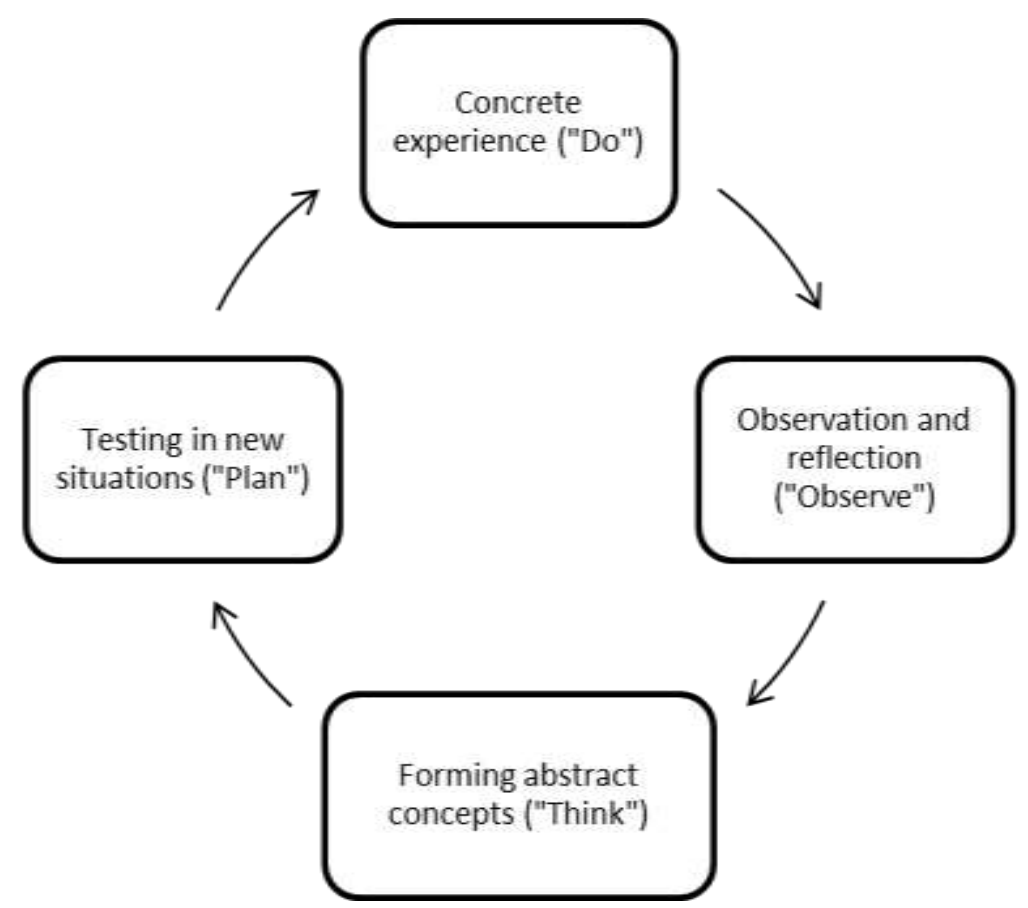

Figure 1. Four-stages of Kolb's experiential learning cycle

hospital and community practitioners, no payment was made for supporting students' EL, and placement site visits are not undertaken. Prior to the placement, students are given a handbook which outlines their responsibilities while on placements as well as the learning objectives for all four years. Students also attend a preparation briefing workshop which covers topics such as professionalism, expectations, and dealing with different behaviours. Workshops teaching them about how to write reflections are also held. Tutors are sent a handbook which details their role as well as the learning outcomes the students have to achieve each year.

Post-placement, students are required to submit reflective diaries on their placement experience for assessment by members of academic staff including GPhC-registered pharmacists, some of whom are responsible for oversight of the EL programme. Students are not required to provide feedback on the placement site or tutors, and tutors are also not required to provide any formal feedback to the university. Students may also undertake paid or unpaid summer placements in community, hospital, and primary care practice but students bear the sole responsibility of planning these placements and they are not part of the University requirements for study. Summer placements and part-time work are optional and do not contribute to EL hours.

In 2011, the GPhC introduced the Standards for the Initial Education and Training of Pharmacists which mandated that all undergraduate MPharm programmes in the UK

\begin{tabular}{|c|c|c|}
\hline \multicolumn{3}{|c|}{ Table 1. Placement allocation by year and site } \\
\hline Year of study* & Community practice & Hospital practice \\
\hline 2 & $2 \times 1 / 2$ days & $1 \times 1 / 2$ day \\
\hline 3 & $6 \times 1 / 2$ days & $1 \times 1 / 2$ day \\
\hline 4 & $8 \times 1 / 2$ days & $1 \times$ day \\
\hline 5 & 10 days in one or two areas of practice \\
\hline $\begin{array}{l}\text { *In this School, students start the first year of the MPharm } \\
\text { programme in Year 2. }\end{array}$ \\
\hline
\end{tabular}

include EL in their curriculum. ${ }^{11}$ This then prompted an increase in EL adopted by the various universities. ${ }^{12}$ However, there have been few studies undertaken in the UK since then to obtain feedback from current students on what they think of the EL, what works for them, and what doesn't. As such the objective of this study was to obtain students' perception of the EL. As the School of Pharmacy prepares for a potential new programme, feedback from students about the EL would be of great importance to identify gaps and areas for improvement.

\section{METHODS}

\section{Data and participants}

The TELL Project is a Three-60 degree evaluation of the ExperientiaL Learning at the School of Pharmacy, where the prime objective is to allow students, graduates, tutors, and stakeholders to TELL us what they think of the EL and what they want from it. We report here the findings from the study involving undergraduates of the MPharm programme.

\section{Study design}

This was a cross-sectional survey of undergraduates of the MPharm programme. Data collection occurred over a three-month period between March and June 2019. The university ethics committee confirmed that ethical approval was not required for this evaluation. The survey was hosted on an online platform, Qualtrics, and an anonymous link along with the Participant Information Sheet was placed on the University virtual learning environment. No financial incentives were offered and a reminder email was sent after one month. Number of students registered by year was as follows: Year 2 (136), Year 3 (116), Year 4 (140), and Year 5 (104). Assuming an overestimated response distribution of $50 \%$, a minimum effective sample size of 81 was needed to achieve a confidence interval of $95 \%$ and a $10 \%$ margin of error. ${ }^{13}$ 


\begin{tabular}{|c|c|c|c|c|c|}
\hline & Total, n (\%) & Year 2, n(\%) & Year 3, n(\%) & Year 4, n(\%) & Year 5, n(\%) \\
\hline \multicolumn{6}{|l|}{ Gender } \\
\hline Female & $89(74.2)$ & $22(64.7)$ & $26(81.3)$ & $29(76.3)$ & $12(75.0)$ \\
\hline Male & $27(22.5)$ & $11(32.4)$ & $5(15.6)$ & $7(18.4)$ & $4(25.0)$ \\
\hline Non-binary & $1(0.8)$ & $1(2.94)$ & $0(0)$ & $2(5.26)$ & $0(0)$ \\
\hline Prefer not to say & $3(2.5)$ & $0(0)$ & $1(3.13)$ & $0(0)$ & $0(0)$ \\
\hline Part-time job in community pharmacy & $87(72.5)$ & $18(52.9)$ & $27(84.4)$ & $32(84.2)$ & $10(62.5)$ \\
\hline \multicolumn{6}{|l|}{ Summer placement } \\
\hline Hospital and community & $36(30.0)$ & $7(20.6)$ & $6(18.8)$ & $16(42.1)$ & $7(43.8)$ \\
\hline Community & $19(15.8)$ & $1(2.94)$ & $3(9.38)$ & $7(18.4)$ & $4(25.0)$ \\
\hline Hospital & $6(5.0)$ & $0(0)$ & $1(3.13)$ & $2(5.26)$ & $0(0)$ \\
\hline Hospital and primary care & $1(0.83)$ & $1(2.94)$ & $0(0)$ & $0(0)$ & $0(0)$ \\
\hline All three settings & $2(1.67)$ & $0(0)$ & $0(0)$ & $1(2.63)$ & $1(6.25)$ \\
\hline \multicolumn{6}{|l|}{ Future area interested to work in } \\
\hline Hospital & $46(38.3)$ & $17(50.0)$ & $13(40.6)$ & 12 (31.6) & $4(25.0)$ \\
\hline Community & $28(23.3)$ & $8(23.5)$ & $7(21.9)$ & $9(23.7)$ & $4(25.0)$ \\
\hline Primary care & $17(14.2)$ & $1(2.94)$ & $4(12.4)$ & $8(21.1)$ & $4(25.0)$ \\
\hline Don't know & $24(20.0)$ & $7(20.6)$ & $1(3.13)$ & $7(18.4)$ & $3(18.8)$ \\
\hline
\end{tabular}

The survey was a six-item anonymous self-report consisting of one open-ended and five closed-ended questions, the latter utilising five-point Likert-type scales ranging from strongly disagree (1) to strongly agree (5). The survey contained questions assessing students' perceptions on the effectiveness of the EL, tutors and placements sites, and organisation and structure of the EL. Demographic details such as summer placement experience, part-time work in community pharmacy, and future areas of interest to work in were also collected. Respondents were allowed to omit responses to the open-ended question if desired. The survey was developed based on UK educational practice, the standards set by the GPhC, the study objectives, and a review of the literature. ${ }^{11}$ Face and content validation was done by five academics with varying expertise in EL and pharmacy education, one English expert, one hospital pharmacist, and two community pharmacists, one of whom was working with the contractor negotiating body, Community Pharmacy Scotland. The survey was also pilot tested on three academics. Following the pilot study, suggestions were given on ways to improve the technical aspects of the survey, and these were amended accordingly. The survey took approximately five to 10 minutes to complete.

\section{Data analysis}

Baseline demographic data were presented using descriptive statistics. To create a composite picture of what respondents disagreed and agreed on for questions employing the five-point Likert scale, responses were collapsed to a three-point scale (agree, neutral, disagree), where the scores for the first two columns ("strongly disagree" and "disagree") were added up to show what they disagreed on, while the scores for the last two columns ("agree" and "strongly agree") were totalled to show what they agreed on. Mean values of students' feedback on tutors as well as the structure and effectiveness of the EL were generated by tabulating their responses on the five-point Likert scale, which were numbered as follows: 1 - Strongly disagree, 2 - disagree, 3 - neutral, 4 - agree, 5 - strongly agree.

General linear regression was employed to examine predictors of perceptions of undergraduates with regard to the effectiveness of the EL in developing their professionalism and communication, clinical, and technical skills. The same variables were used to examine predictors on feedback of tutors and placement sites. The following three independent variables were included in the models: year of study, if they did a summer placement, and if they had a part-time job. The latter two variables were selected as research has shown that they have an impact on students' perception of EL. ${ }^{14}$ Variance Inflation Factor (VIF) values were inspected for the possibility of multicollinearity, with results higher than 10 being considered as indicative of this problem. The a priori level of significance was 0.05 , and all analyses were performed using Microsoft Excel and SPSS 24.0 statistical software (SPSS Inc, Chicago, IL, USA).

Thematic content analysis was performed on the openended comments, as it allows researchers to not just focus on code-counting but highlight as well key themes that emerge. ${ }^{15}$ All open-ended comments were read and reread and keywords were identified. These keywords were sorted into categories, and then subjected to thematic analysis. ${ }^{16}$ Respondents of open-ended comments were identified according to their year of study (e.g. Y2) and part-time job status $(P ; Y$ indicating they had part-time jobs).

\section{RESULTS}

There were 139 responses (Response rate: 28\%) and of these, 18 only provided demographic details and were removed. As such, 121 responses were analysed and of these, 102 answered all sections, while one did not provide demographic details. Mean age of respondents was 21.2 ( $S D=3.68)$ and $87(72.5 \%)$ had a part-time job, while 56 (46.7\%) did not undertake any summer placements. With regard to future areas they wanted to work in, five noted 'other' areas which included industry and research (Table 2).

Overall, students were positive about the effectiveness of $\mathrm{EL}$ in developing their professionalism and communication, clinical, and technical skills (Table 3). General linear regression found that Year 3 and Year 4 students had significantly more negative views about the effectiveness of $E L$ in developing their clinical skills compared to those in Year 2. With regard to the effectiveness of EL in developing their technical skills, Year 3 students had significantly more 


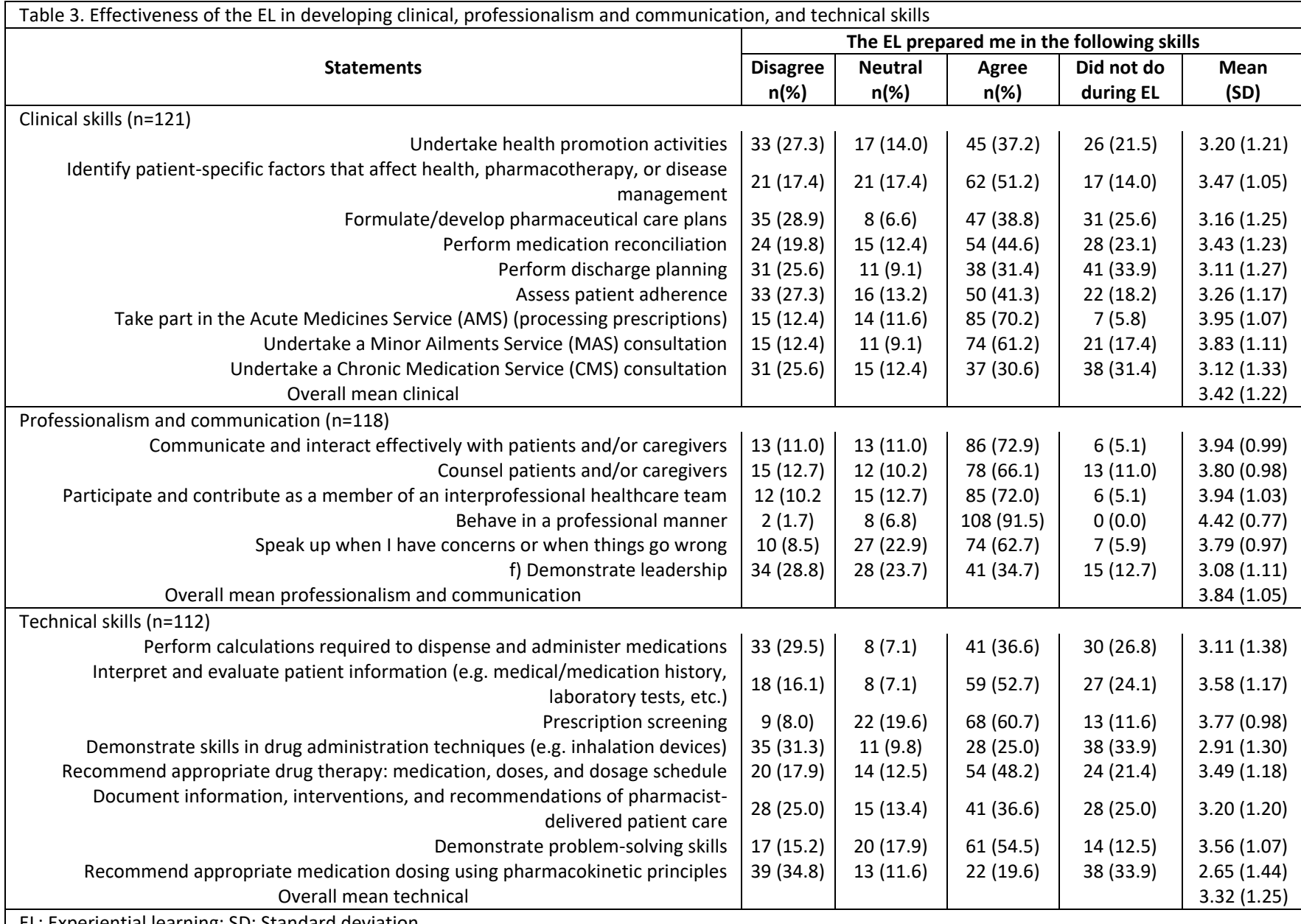

negative views while Year 4 students had significantly more positive views, compared to those in Year 2 (Table 4).

Calculation of mean revealed that students were more positive about their experience with tutors at the hospital $(M=3.79, S D=1.18)$, compared to the community $(M=3.30$, $S D=1.27)$. Students were ambivalent with regard to the preparedness of tutors in the community, as well as their perception of their overall experience in the community setting (Table 5). General linear regression found no significant relationship between feedback on tutors and placement site, and the independent variables. With regard to structure and coordination, overall perception was neutral $(M=3.39, S D=1.27)$. More than $70 \%$ disagreed that hospital attachments were sufficient, while more than $80 \%$ agreed that their part-time work should contribute toward their EL hours (Table 6).

Forty-five students left open-ended comments, with five, 18,12 , and 13 comments from Years $5,4,3$ and 2 respectively. Responses were an average of 93 words, with a range of 19 to 210 words. There were nine positive and 72 negative comments about community placements, with the latter mainly related to placement experience and tutors. For the hospital settings, there were 40 positive comments and 13 negative comments with the majority highlighting the limited duration of attachment. The number of comments according to the different categories is illustrated in Table 7.

Thematic analysis revealed three key themes: (1) Perceived experience of placements, (2) Impact of tutors and site on placement experience, and (3) Key influence of having a part-time job. These are described below.

\section{Theme 1: Perceived experience of placements}

Hospital placements received positive feedback, with students describing it as "brilliant" and "extremely beneficial". Among the benefits noted were the fact that the placements influenced their decision to work in the hospital, and that it gave them a good insight into the daily role of a hospital pharmacist. One noted that it was:

\begin{tabular}{|c|c|c|c|c|c|c|c|c|}
\hline \multirow[b]{2}{*}{ Model } & \multicolumn{4}{|c|}{ Clinical skills $\left(R^{2}=012\right)$} & \multicolumn{4}{|c|}{ Technical skills $\left(R^{2}=0.25\right)$} \\
\hline & Adj.b & $95 \% \mathrm{Cl}$ & t-stat & $p$-value & Adj.b & $95 \% \mathrm{Cl}$ & t-stat & p-value \\
\hline YearA ${ }^{a}$ & -0.933 & $-1.51:-0.36$ & -3.24 & 0.020 & -1.09 & $-1.78:-0.40$ & -3.13 & 0.002 \\
\hline YearB ${ }^{b}$ & -0.745 & $-1.31:-0.18$ & -2.64 & 0.010 & 0.669 & $0.04: 1.29$ & 2.13 & 0.036 \\
\hline
\end{tabular}




\begin{tabular}{|c|c|c|c|c|c|c|c|c|}
\hline Experiential learning statements & \multicolumn{4}{|c|}{ Community ( $n=104)$} & \multicolumn{4}{|c|}{ Hospital ( $\mathrm{N}=104)$} \\
\hline $\begin{array}{l}\text { b) Workload allocation during my EL was carefully } \\
\text { planned by tutors }\end{array}$ & $46(44.2)$ & $19(18.3)$ & $39(37.5)$ & $2.88(1.34)$ & $10(9.6)$ & $17(16.3)$ & $77(74.0)$ & $3.97(1.03)$ \\
\hline c) Tutors were prepared for my arrival & $38(36.5)$ & $18(17.3)$ & $48(46.2)$ & $3.13(1.36)$ & $3(2.9)$ & $6(5.8)$ & $95(91.3)$ & $4.36(0.84)$ \\
\hline d) Tutors were able to spend time with me $(n=103)$ & $27(26.2)$ & $17(16.5)$ & $59(57.3)$ & $3.42(1.21)$ & $4(3.9)$ & $7(6.8)$ & $92(89.3)$ & $4.38(0.82)$ \\
\hline $\begin{array}{l}\text { f) The EL site allowed me to interact with patients } \\
(n=103)\end{array}$ & $14(13.6)$ & $14(13.6)$ & $75(72.8)$ & $3.79(1.09)$ & $48(46.6)$ & $14(13.6)$ & $41(39.8)$ & $2.91(1.32)$ \\
\hline g) It was easy to get to my EL site(s) & $25(24.0)$ & $13(12.5)$ & $66(63.5)$ & $3.54(1.36)$ & $33(31.7)$ & $15(14.4)$ & $56(53.8)$ & $3.33(1.31)$ \\
\hline $\begin{array}{l}\text { h) The EL site had enough space to accommodate } \\
\text { me as a student }\end{array}$ & 15 (14.4) & 20 (19.2) & $69(66.3)$ & $3.69(1.10)$ & 2 (1.9) & $13(12.5)$ & $89(85.6)$ & $4.17(0.79)$ \\
\hline i) Overall, I had a good experience in the EL site & $23(22.1)$ & $28(26.9)$ & $53(51.0)$ & $3.38(1.14)$ & $4(3.8)$ & 15 (14.4) & $85(81.7)$ & $4.19(0.89)$ \\
\hline
\end{tabular}

"Much more interactive and engaging and a very worthwhile glimpse into the role of a hospital pharmacist." (Y4, PY)

Two commented that the placements were better than community placements. Students did, however, lament the short placement duration as well as limited allocation in the hospital, which were thought to restrict the placement experience. Indeed, they felt a longer duration would allow them to get a better idea about the different sectors it involved. One Year 4 student commented:

"The full day hospital placement provided a very good insight as to what a clinical pharmacist does on a daily basis as opposed to the half days we had in the last 2 years where there was a lack of time." (Y4, PY)

Students were very critical of their experience in the community, describing it as a "waste of time". The main complaint students had was the fact that they were often used as a free set of hands and tasked with preparing Dosette boxes (a multicompartment compliance aid) or dispensing, which they felt did not contribute to their learning. This is illustrated in the following comment:
"I popped out tablets for 2 hours and dispensed prescriptions for the rest of the time. When I went back for a second afternoon, I made up dosette boxes for a few hours and then they said I could leave." (Y2, PY)

This prompted one student to say,

"There seems to be a pertinent issue with community pharmacists elsewhere not understanding why we are supposed to be there; that is to learn and meet the requirements of our competencies to be completed, not dispense generic prescriptions, clear shelves, make up dosette boxes or be the equivalent of an extra staff member." (Y4, PY)

As they were mainly dispensing, this did not allow for much or any time to complete their own learning objectives, obtain a better exposure to the different processes and roles of a community pharmacist, or "...engage with customers or see a consultation." Indeed, many noted that there wasn't much teaching or that they didn't learn anything from their community placements:

"I had little opportunity to spend time with patients

\begin{tabular}{|c|c|c|c|c|}
\hline Statements* & $\begin{array}{l}\text { Disagree } \\
\mathrm{n}(\%)\end{array}$ & $\begin{array}{c}\text { Neutral } \\
\mathrm{n}(\%)\end{array}$ & $\begin{array}{l}\text { Agree } \\
\mathrm{n}(\%)\end{array}$ & Mean (SD) \\
\hline $\begin{array}{l}\text { a) I think the number of EL hours I have spent in community pharmacy will be sufficient to } \\
\text { prepare me for practice }\end{array}$ & $29(28.4)$ & $15(14.7)$ & $58(56.9)$ & $3.41(1.22)$ \\
\hline $\begin{array}{l}\text { b) I think the number of EL hours I have spent in hospital pharmacy will be sufficient to } \\
\text { prepare me for practice }\end{array}$ & $74(72.5)$ & $15(14.7)$ & $13(12.7)$ & $2.10(1.07)$ \\
\hline $\begin{array}{l}\text { c) I should be allowed to undertake EL in other settings e.g. hospices, general practice } \\
\text { surgeries etc. }\end{array}$ & $1(1.0)$ & $7(6.9)$ & $94(92.2)$ & $4.43(0.67)$ \\
\hline d) Part-time pharmacy employment should be recognised as EL & $6(5.9)$ & $10(9.8)$ & $86(84.3)$ & $4.26(0.90)$ \\
\hline e) I should be allowed to select my own EL sites & $16(15.7)$ & $24(23.5)$ & $62(60.8)$ & $3.68(1.11)$ \\
\hline f) I was able to complete the activities outlined in the EL handbook & $31(30.4)$ & $20(19.6)$ & $51(50.0)$ & $3.28(1.24)$ \\
\hline g) EL should take place in every year of the MPharm & $11(10.8)$ & $7(6.9)$ & $84(82.4)$ & $4.24(1.02)$ \\
\hline h) I want to be able to do my EL during my summer break & $42(34.7)$ & $26(25.5)$ & $34(33.3)$ & $2.91(1.31)$ \\
\hline i) Attendance at EL sites should be recorded by tutors & $22(21.6)$ & $29(28.4)$ & $51(50.0)$ & $3.40(1.15)$ \\
\hline j) There should be a formal process for me to provide feedback on my EL experience & $9(8.8)$ & $22(21.6)$ & $71(69.6)$ & $3.80(0.96)$ \\
\hline k) I receive sufficient support from the university on matters related to $E L$ & $27(26.5)$ & $28(27.5)$ & $47(46.1)$ & $3.21(1.01)$ \\
\hline I) The EL is well coordinated between the university and the tutors & $37(36.3)$ & $29(28.4)$ & $36(35.3)$ & $2.94(1.08)$ \\
\hline m) The EL is unnecessary & $65(63.7)$ & $17(16.7)$ & $20(19.6)$ & $2.25(1.22)$ \\
\hline n) Overall, I think the EL will prepare me for practice & 21 (20.6) & $15(14.7)$ & $66(64.7)$ & $3.56(1.07)$ \\
\hline
\end{tabular}




\begin{tabular}{|c|c|c|}
\hline Categories* & \multicolumn{2}{|c|}{ Number of comments } \\
\hline Organisation and structure $(\mathrm{n}=29)$ & \\
\hline Hospital placements too short or more needed & \multirow{2}{*}{\multicolumn{2}{|c|}{14}} \\
\hline Placement in other settings e.g. primary care & & 7 \\
\hline Community placements too long & \multicolumn{2}{|c|}{6} \\
\hline More experiential learning needed & \multicolumn{2}{|c|}{2} \\
\hline Placement sites too far way & \multicolumn{2}{|c|}{4} \\
\hline Gaps in communication between university and site & \multicolumn{2}{|c|}{2} \\
\hline \multirow{4}{*}{$\begin{array}{l}\text { Part-time work }(\mathrm{n}=23) \\
\begin{array}{r}\text { Similar tasks done during part-time work or didn't learn anything new from EL } \\
\text { Better experience compared to } E L\end{array} \\
\text { Experiential learning unnecessary or should be optional }\end{array}$} & \\
\hline & \multirow{2}{*}{\multicolumn{2}{|c|}{$\begin{array}{l}7 \\
6\end{array}$}} \\
\hline & & \\
\hline & \multicolumn{2}{|c|}{5} \\
\hline \multirow[t]{2}{*}{ Experience of placement $(n=57)$} & Community & Hospital \\
\hline & $\begin{array}{c}2 \\
26\end{array}$ & $\begin{array}{c}20 \\
3\end{array}$ \\
\hline \multicolumn{3}{|l|}{ Tutors and site $(n=48)$} \\
\hline Lack of engagement or interaction & 7 & 1 \\
\hline Preparation $\quad$ Actively engaged & 4 & 8 \\
\hline Well-prepared or organised for students & 1 & 12 \\
\hline Not prepared & 7 & 0 \\
\hline Not aware students were coming for placements & 5 & 0 \\
\hline Too busy & 2 & 0 \\
\hline
\end{tabular}

and was in the dispensary which wasn't very patient facing. I spent most of my time dispensing and wasn't shown any new processes... I was standing around without much to do at times, despite asking for tasks and offering to do things. I think my time would have been better spent in another pharmacy type setting." (Y3, PY)

With regard to challenges, logistics was mainly highlighted by students, with many lamenting the far distances they had to travel to get to their placement sites. It was thus suggested that placements should take into consideration where students lived. Students also noted gaps in communication between the university and placement site, attributing this to the reason why some tutors were not aware that students were coming.

\section{Theme 2: Impact of tutors and site on placement experience}

Placement experience was said to be dependent on the tutors as well as placement sites, with one student noting,

"EL experience varies a lot depending on which pharmacies we are assigned to. There is not much consistency in what different tutors offer - some students get to engage with patients and take an active role, and others are expected to just watch and ask questions." (Y3, PY)

This was especially true in community pharmacies, with busy sites impeding effective learning, as noted by a student:

"My community pharmacy was very busy and I did not get much chance to practice things myself and learn." (Y2, PN)

Students complained that tutors in the community were often unaware that they were coming, and had nothing planned for their attachment. This is illustrated in the following comment,
"I was asked what I wanted to do when I arrived as no plans had been thought through and I was left to do what I wanted." (Y2, PY)

Students also commented on the lack of support and engagement by tutors as they were often too busy. Due to this, students often felt like they were in the way and a distraction:

"Community pharmacy placement is more challenging as the pharmacist is always very busy checking prescriptions, that they have little time to spend with me." (Y4, PY)

On the contrary, tutors from the hospital received very favourable feedback, with many students noting that they were well-organised and had tasks planned for students. One student shared,

"Hospital placement was much better, more informative and easy to reach. Better organised and showed me a lot of areas in the hospital and what pharmacists do to sort out issues and how they deal with new patients and patients getting discharged." $(\mathrm{Y} 2, \mathrm{PN})$

Hospital tutors were very helpful and eager to equip students with as much information as possible to ensure they had a good placement experience. Tutors made the effort to demonstrate the necessary skills to students, and time was also allocated to allow for discussions in greater depth:

"The tutor was very keen and professional in demonstrating what he does and was actively engaging us through asking us clinical questions."(Y4, PY)

\section{Theme 3: Key influence of having a part-time job}

Having a part-time job in the community seemingly had a major influence on students' perceived placement experience and feedback, with students noting that community placements were pointless or should not be 
compulsory as they were learning more from their jobs and were not learning new skills from their placements. Indeed, students noted that they were able to complete most of their learning outcomes at their jobs. One reflection stated,

"Most (if not all) students have part time jobs in community pharmacy by the time they reach final year which they learn a lot more from and would be a better use of time to encourage overtime etc. instead of carrying out a community placement." (Y2, PY)

A few did note that the familiarity at their work-site allowed for better learning, as students had, among others, already established a rapport with work staff. One student shared the following reflection:

"People in part-time pharmacy work get a much better chance in the workplace to enhance their clinical skills and problem-solving ability due to being in a familiar environment without the need to travel elsewhere, meet people they don't know and familiarise themselves to another system that hinders their ability to move on to more important topics like prescription checking, clinical and legal matters and patient monitoring and counselling because they have a pre-established positive relationship with their colleagues and can ask questions much more regularly and freely."(Y4, PY)

It also impacted their perception of placement allocation, with many noting that community placements were too long especially in later years, and especially by those who already had part-time jobs. Indeed, one student noted that it felt like the university was trying to steer students toward a career in community pharmacy, thus side lining the other practice sites:

"Overall not focus on community so much as many of us know what that's like as we work in one, and help experience different types of pharmacy we haven't be exposed to, "broaden our horizons" and help us find the perfect sector of pharmacy for each student. It just seems like you're just pushing us all to become community pharmacists and don't want us to go into other sectors." (Y3, PN)

As such, there were calls for more placements in the hospital and emerging settings such as primary care as they would provide experiences that were different from their part-time jobs. One student commented that

“...having no opportunities for primary care etc. doesn't prepare us for practice if we don't have the chance to see what it's like." (Y3, PY)

\section{DISCUSSION}

This study sought to assess students' perception of their EL experience. Students were generally positive about their experience in the hospital, despite the lack of time spent there. On the contrary, feedback about community placements was largely negative, especially with regard to the tutors. Having a part-time job appeared to have a major impact on students' perceived experience of their placements.
The majority of students were not happy with the limited time spent in the hospital. There is much ambiguity with regard to placement duration, with some preferring shorter placements, and others preferring the opposite. ${ }^{7,8,17}$ More important than simply focusing on duration, there should be a focus instead on quality - ensuring placements are not too short that they only provide a superficial experience where students are merely 'tourists', and not too long that tasks become too repetitive and the experience turns more to 'working' instead of 'learning'. ${ }^{18,19}$ One way of ensuring this is by adopting a mixture of structure and flexibility in placements. The latter is especially crucial given the dynamic nature of the healthcare environment which might pose a barrier to students achieving their learning objectives if they were too rigid. ${ }^{9}$ Flexibility will also allow for more consideration of the different student learning styles, needs, and interests. ${ }^{9,20}$ A mixture of structure and flexibility will also assist students in writing reflections which are useful, while at the same time enabling greater depth of reflection. ${ }^{9,21}$

There were numerous comments about students being used as an extra pair of hands during their placements in the community, with minimal to no teaching taking place. This has been highlighted previously, and indeed there have been concerns about the quality of placements, particularly in the community setting., ${ }^{9,18,22}$ While pharmacists see the value in EL, they do face a burden when taking on students for placements, as they do not have protected time, resulting in an increase in workload and stress when students are there, and limited time to engage with students. ${ }^{2,23-28}$ This is similar to that highlighted in this study, where many perceived community tutors as too busy to engage with students. However, as placements in the hospital are of a shorter duration (Table 1 ), it is most likely easier to organise and for tutors to spend time with students.

Community placements were longer in duration, which likely allowed for opportunistic learning and more patient interactions to occur. Nevertheless, students still had a more negative perception of community placements, despite the fact that there was limited interaction with patients in the hospital setting. This can be explained by the psychology of learning environments where being in, what is perceived as, a more positive environment will elicit more favourable emotional responses to that place, and lead to enhanced learning. ${ }^{29}$ Kaplan and Kaplan's Predictors of Environmental Preference is also significant here, where four cognitive predictors of environmental preference have been highlighted namely coherence, complexity, legibility, and mystery. ${ }^{30,31}$ The latter would seem appropriate to explain students' perception of a better experience in the hospital environment given the novelty of the environment and the level of intrigue it presents to students. This contrasts with the community setting, which the majority of students already work in, and is thus perceived as being less mysterious. Due to having a part-time job, students also have higher expectations of community sites versus hospitals sites, and have been found to be more critical when their expectations were perceived as not met. ${ }^{14}$

In 2019, the Scottish Government announced the Additional Cost of Teaching Pharmacy (ACTp) funding where placement sites will be provided with funds to 
support the training of students. This money can be used to hire additional staff when students are there, allowing tutors to fully engage with students. ${ }^{32}$ Indeed, studies have found that tutors view money as a valuable incentive to compensate them for their time, and providing monetary compensation was found to improve the relationship between tutors and the university, as well as increase tutor retention, recruitment, and loyalty. ${ }^{27,28,33}$

Tutor training is key to ensure tutors are aware of their roles and responsibilities, as well as feedback from students. There has indeed been a call for more tutortraining programmes as tutors have acknowledged that they lack the necessary skills to supervise students. ${ }^{10,34,35}$ The Preparation for Facilitating Experiential Learning Training (PFEL) introduced in 2019 by NHS Education for Scotland (NES) and the two universities in Scotland should be made compulsory for all tutors as it will prepare them on how to provide quality experiences for students, which includes giving feedback. The latter is a practice not commonly adopted by tutors, as noted in our findings, and a skill they often struggle with. ${ }^{2,34}$ During these sessions, universities should also signpost relevant support staff tutors can access should they face challenges or have questions while tutoring students.

Stakeholder such as pharmacists and academics have highlighted that the lack of quality assurance of tutors was a barrier to the training of pharmacists. ${ }^{22}$ While the GPhC has stipulated in the Standards that tutors and placement sites for undergraduate programmes must be qualityassured, there is no specification as to how or how frequently this should be undertaken. ${ }^{11}$ Indeed, a recent nationwide survey conducted in the UK found that less than five universities had regular and standardised placement visits once or more per year. Survey respondents also ranked the lack of quality assurance of tutors as the third most important challenge they faced with EL. ${ }^{12}$

In a survey of placement tutors in the United States (US), there was strong support for site visits by the university, with tutors acknowledging that it assisted them in planning and improving the placement experience for the students, and enabled them to address issues related to students and the universities' expectations of them. The majority preferred monthly visits. ${ }^{36}$ As such to ensure that the sites provide an optimal learning environment which will allow students to obtain the appropriate practical experience unhindered, it would seem prudent that regulated and ongoing site visits should be undertaken, similar to that currently being undertaken by NES on pre-registration sites and tutors. ${ }^{36,37}$ This is, however, not without its barriers. In the US, students have to complete 300 mandated hours of placements, which are typically undertaken in blocks. As EL in the UK is limited to short periods, monthly or frequent visits may then not be feasible or practical. To accommodate this, Schools of Pharmacy can potentially look to conducting quality assurance 'visits' virtually or even over the phone, as is practised elsewhere. ${ }^{12}$

In the current GPhC model, pre-registration pharmacists are allowed to delegate tutoring, but not assessment, duties to other competent pharmacy staff such as technicians and pharmacy assistants. A similar model is followed for undergraduate placements, highlighting the need to include them in quality assurance measures. While it would not seem feasible to include other pharmacy staff in training sessions, tutors attending tutor-training programmes must be told to ensure these staff are aware of their roles and responsibilities when tutoring students.

More than $80 \%$ of respondents agreed that part-time work should contribute toward their EL hours. This was supported by respondents in the aforementioned nationwide survey of UK universities, where more than $50 \%$ believed that students should receive EL credit for pharmacy employment. ${ }^{12}$ There is, however, no stipulation in the Standards which allow students to be excluded from EL because of their part-time work. The School of Pharmacy's philosophy is that all students should have equitable access to EL to enable the School to ensure all students have a similar experience, independent of their part-time work. In addition, the Standards stipulate that students should practice in a safe and effective manner. To achieve this, EL should be progressive, where students deal with issues with increasing complexity until sufficient comprehension and competency is achieved. ${ }^{11}$ This will be difficult to monitor and govern if students are allowed to undertake EL at their part-time jobs.

Discussions with graduates as part of our TELL project have also revealed that during their part-time jobs they mainly assumed the role of a technician as opposed to a pharmacist, and the focus was more on working instead of learning. ${ }^{14}$ Crucially, there is no time for reflection. A central element of Kolb's experiential learning theory is reflection of the experience which helps students make the link between theories and the knowledge acquired in university, with the intricacies of practice. Indeed, effective learning is thought to occur only when students have completed all four stages of Kolb's experiential learning model. ${ }^{38}$ Reflection is also a crucial practice, especially for pharmacy students and in higher education, as it develops self-regulated, critical-thinking, and problems-solving skills important arsenals for healthcare professionals who traditionally work in dynamic work settings. ${ }^{39}$ While it has been argued that tutors will be more amenable to putting in the effort to train students who will then work for them, it is imperative that should this be allowed, that it is wellstructured similar with their EL and closely regulated. ${ }^{40}$

More than $90 \%$ of respondents wanted to be able to undertake placements in other settings such as primary care, a call further underlined in the open-ended responses. Projected increases in ageing and the number of those living with multiple comorbidities in the UK will likely place a burden on the primary care system. ${ }^{41}$ To support the shift from care in the institutions to primary care and to help manage the increasing complexity of cases being treated in primary care, Achieving Excellence in Pharmaceutical Care - a Strategy for Scotland, was launched by the Scottish government where one of the key objectives is to prepare pharmacists to assume positions in this sector. ${ }^{42-44}$ As such, there is a need to adopt these emerging placement sites to provide students with the necessary exposure and training, as already done by a number of universities. ${ }^{12}$ The ACTp funding will also help funnel resources to allow for more placements in these sites. ${ }^{45}$ Given the multidisciplinary nature of primary care, 
this will also require more interprofessional training opportunities to be embedded within the placements - a requirement also stipulated in the Standards by the $\mathrm{GPhC}{ }^{11}$

\section{Limitations}

There was a low response rate, however the number attained fulfilled the minimum sample size requirement. Demographics of respondents were also representative of the current student population, which are predominantly females. The survey was not pilot tested on undergraduates. However, pilot testing was undertaken involving academics who were recent graduates of the MPharm programme and who had recently undergone EL while at the School of Pharmacy. Responses with missing data were included in the analyses, and as such this may limit interpretation of the results. Although the researchers sought participation from students to participate in qualitative interviews, there were no volunteers. As such, researchers were not able to explore in more depth the findings and themes as well as other factors which might have impacted students' views and experience such as organization of placements. There should be an effort in future to explore salient issues identified through qualitative interview to provide more depth to the findings.

\section{CONCLUSIONS}

Undergraduate pharmacy students voiced concerns about placement duration and tutors, the latter underlining the importance of tutor-training programmes to ensure tutors are aware of the responsibilities as well as expectations from Schools. While increasing the duration of placements may not be feasible for all universities due to issues with funding and resources, Schools could focus instead on ensuring placements are well-structured yet flexible to accommodate different learning styles and interests of undergraduates. Quality assurance measures are also imperative to ensure all tutors and placement sites are able to provide students with an effective and equitable placement experience. Changes should be made to the curriculum to include emerging areas such as primary care as a placement site, and further investigations should be undertaken to assess the advantages and disadvantages of allowing undergraduate students to undertake their EL at their place of work.

\section{ACKNOWLEDGEMENTS}

We thank the following for validating the survey, as well as taking part in the pilot study: Emma Dunlop, Adam Osprey, Pernille Sorensen, Gazala Akram, Natalie Weir, Zahra Rattray, Balamurugan Tangiisuran, Zainol Akbar bin Zainal, Louise Evans, Elizabeth Chong, Carole Chung, Alison Thomson

\section{CONFLICT OF INTEREST}

The authors report no conflict of interest.

\section{FUNDING}

This study was supported by an educational grant received from NHS Education for Scotland (NES).

\section{References}

1. Kolb DA. Experiential learning: Experience as the source of learning and development. Englewood Cliffs, NJ: Prentice Hall; 1984.

2. Fejzic J, Henderson A, Smith NA, Mey A. Community pharmacy experiential placement: Comparison of preceptor and student perspectives in an Australian postgraduate pharmacy programme. Pharm Educ. 2013;13(1):15-21.

3. McGivney MS, Hall DL, Stoehr GP, Donegan TE. An introductory pharmacy practice experience providing pharmaceutical care to elderly patients. Am J Pharm Educ. 2011;75(8):159. https://doi.org/10.5688/ajpe758159

4. Naro P, Beall J, Wensel T, Click E, McCullough B, Heard A. Impact of a Community Pharmacy Based Health, Wellness and Prevention Introductory Pharmacy Practice Experience. Pharm Educ. 2017;17(1):154-158.

5. Agness $C F$, Huynh $D$, Brandt N. An introductory pharmacy practice experience based on a medication therapy management service model. Am J Pharm Educ. 2011;75(5):82. https://doi.org/10.5688/ajpe75582

6. Winn P, Turner CJ. Description and Evaluation of an MPharm Practice-based Experience Pilot Program. Am J Pharm Educ. 2016;80(9):151. https://doi.org/10.5688/ajpe809151

7. McCartney J, Boschmans S-A. South African pharmacy student perspectives of a hospital-based experiential learning programme. Pharm Educ. 2018;18(1):29-40.

8. Burrows J, Dall'Alba G, Caze AL. Becoming pharmacists: Students' understanding of pharmacy practice at graduation from an Australian University. Curr Pharm Teach Learn. 2016;8(6):729-741. https://doi.org/10.1016//.cptl.2016.08.007

9. Stupans I Owen S. Planning and scaffolding for learning in experiential placements in Australian pharmacy schools. AsiaPacific Journal of Cooperative Education. 2009;10(1):29-37.

10. Wuller WR, Luer MS. A sequence of introductory pharmacy practice experiences to address the new standards for experiential learning. Am J Pharm Educ. 2008;72(4):73. https://doi.org/10.5688/aj720473

11. General Pharmaceutical Council. Future pharmacists: Standards for the initial education and training of pharmacists. London, UK: General Pharmaceutical Council; 2011

12. Jacob SA, Boyter AC. Nationwide survey of experiential learning in MPharm programmes in UK Universities. Int J Pharm Pract. 2020;28(2):121-129. https://doi.org/10.1111/ijpp.12521

13. Raosoft. Online sample size calculator. Available at: http://www.raosoft.com/samplesize.html (accessed Feb 24, 2020).

14. Jacob SA, Boyter AC. "My experiences were highly-dependent on the knowledge and enthusiasm of the tutor": graduates' feedback of experiential learning in an MPharm programme Part 1 (TELL Project). Stud Educ Eval. 2020;66(sep):100891. https://doi.org/10.1016/i.stueduc.2020.100891 
15. Haynes-Maslow L, Andress L, Jilcott Pitts S, Osborne I, Baquero B, Bailey-Davis L, Byker-Shanks C, Houghtaling B, Kolodinsky J, Lo BK, Morgan EH, Piltch E, Prewitt E, Seguin RA, Ammerman AS. Arguments Used in Public Comments to Support or Oppose the US Department of Agriculture's Minimum Stocking Requirements: A Content Analysis. J Acad Nutr Diet. 2018;118(9):1664-1672. https://doi.org/10.1016/j.jand.2017.12.005

16. Braun V, Clarke V. Using thematic analysis in psychology. Qual Res Psychol. 2006;3(2):77-101. https://doi.org/10.1191/1478088706ap063oa

17. Prisco JL, Hritcko PM, Feret B, Yorra ML, Todd NE, Kim Tanzer, Basile C, Bonaceto K, Morelli R, Carace N, Szumita A. Assessing experiential education factors contributing to a PGY1 residency match: Pharmacy residency program director and comparative student survey. Curr Pharm Teach Learn. 2018;10(2):146-153. https://doi.org/10.1016/i.cptl.2017.10.020

18. Talley CR. Experiential rotations for pharmacy students. Am J Health Syst Pharm. 2006;63(11):1029. https://doi.org/10.2146/ajhp060190

19. Cox CD. Quantity vs Quality in Experiential Education. Am J Pharm Educ. 2016;80(3):36. https://doi.org/10.5688/ajpe80336

20. Healey M, Jenkins A. Kolb's Experiential Learning Theory and Its Application in Geography in Higher Education. Journal of Geography. 2000;99(5):185-195. https://doi.org/10.1080/00221340008978967

21. Moon JA. A Handbook of Reflective and Experiential Learning: Theory and Practice. United Kingdom: Routledge; 2004.

22. General Pharmaceutical Council. Tomorrow's pharmacy team: responses to the discussion paper. London: General Pharmaceutical Council; 2015

23. Hendry G, Winn P, Wiggins S, Turner CJ. Qualitative Evaluation of a Practice-based Experience Pilot Program for Master of Pharmacy Students in Scotland. Am J Pharm Educ. 2016;80(10):165. https://doi.org/10.5688/ajpe8010165

24. Kassam R, Kwong M, Collins JB. A demonstration study comparing "role-emergent" versus "role-established" pharmacy clinical placement experiences in long-term care facilities. BMC Med Educ. 2013;13:104. https://doi.org/10.1186/14726920-13-104

25. Chaar BB, Brien JA, Hanrahan J, McLachlan A, Penm J, Pont L. Experimental education in Australian pharmacy: Preceptors' perspectives. Pharm Educ. 2011;11(1):166-171.

26. Christner JG, Dallaghan GB, Briscoe G, Casey P, Fincher RM, Manfred LM, Margo KI, Muscarella P, Richardson JE, Safdieh J, Steiner BD. The Community Preceptor Crisis: Recruiting and Retaining Community-Based Faculty to Teach Medical Students-A Shared Perspective From the Alliance for Clinical Education. Teach Learn Med. 2016;28(3):329-336 https://doi.org/10.1080/10401334.2016.1152899

27. Skrabal MZ, Jones RM, Nemire RE, Boyle CJ, Assemi M, Kahaleh AA, Soltis DA, Allen RE, Hritcko PM, O'Sullivan TA, Destache CJ. National survey of volunteer pharmacy preceptors. Am J Pharm Educ. 2008;72(5):112. https://doi.org/10.5688/aj7205112

28. Seo H, Ryu K, Lee S, Noh J, La H, Kim E. Stress, Satisfaction, and Competency of Hospital Pharmacy Preceptors under the New Pharmacy Program in South Korea. Am J Pharm Educ. 2018;82(8):6351. https://doi.org/10.5688/ajpe6351

29. Graetz KA. Chapter 6. The Psychology of Learning Environments. 2006 [cited 28/5/2020]. In: Learning Spaces. Educause. Available at: https://www.educause.edu/ir/library/pdf/PUB7102.pdf (accessed May 28, 2020).

30. Kaplan R, Kaplan S, Brown T. Environmental Preference: A Comparison of Four Domains of Predictors. Environ Behav. 1989;21(5):509-530. https://doi.org/10.1177\%2F0013916589215001

31. Hynes MM, Hynes WJ. If you build it, will they come? Student preferences for Makerspace environments in higher education. Int J Technol Design Educ. 2018;28(3):867-883. https://doi.org/10.1007/s10798-017-9412-5

32. Watson MC, Jacob SA, Jebara T. Evaluation of the 2019 ACTp Pilot [Final Report]. NHS Education for Scotland 2019

33. Brownfield A, Garavalia L, Gubbins PO, Ruehter V. Exploration of Methods Used by Pharmacy Professional Programs to Contract with Experiential Practice Sites. Am J Pharm Educ. 2016;80(2):26. https://doi.org/10.5688/ajpe80226

34. Assemi M, Corelli RL, Ambrose PJ. Development needs of volunteer pharmacy practice preceptors. Am J Pharm Educ. 2011;75(1):10. https://doi.org/10.5688/ajpe75110

35. Gibson M, Sullivan D, Tubbs C, Mirtallo J, Kelley K. Assessment of barriers to providing introductory pharmacy practice experiences (IPPEs) in the hospital setting. Inov Pharm. 2016;7(2):442. https://doi.org/10.24926/iip.v7i2.442

36. Burgett NE, Dennis VC, Wideman SD, Kirkpatrick AE, Randall DL. Pharmacy preceptors' views on the value and optimal frequency of quality assurance visits to advanced pharmacy practice experience sites. Am J Pharm Educ. 2012;76(3):48. https://doi.org/10.5688/ajpe76348

37. Quality Assurance. Available at: https://www.nes.scot.nhs.uk/education-and-training/by-discipline/pharmacy/preregistration-pharmacist-scheme/quality-assurance.aspx (accessed Oct 2, 2019).

38. Kolb AY, Kolb DA. Learning styles and learning spaces: enhancing experiential learning in higher education. Acad Manag Learn Educ. 2005;4(2):193-212.

39. Tsingos C, Bosnic-Anticevich S, Smith L. Reflective practice and its implications for pharmacy education. Am J Pharm Educ. 2014;78(1):18. https://doi.org/10.5688/ajpe78118

40. Darbishire PL, Devine T, Holowatyj MR, Schmelz AN. National survey of introductory pharmacy practice experience programs. scholarship and professional work. Available at: https://digitalcommons.butler.edu/cophs papers/187 (accessed May 28, 2020).

41. Kingston A, Robinson L, Booth H, Knapp M, Jagger C; MODEM project. Projections of multi-morbidity in the older population in England to 2035: estimates from the Population Ageing and Care Simulation (PACSim) model. Age Ageing 2018;47(3):374-380. https://doi.org/10.1093/ageing/afx201

42. Burgess L. Primary Care in Scotland United Kingdom: The Scottish Parliment, 2019.

43. Scottish Government. Achieving Excellence in Pharmaceutical Care - A Strategy for Scotland. Available at: https://www2.gov.scot/Resource/0052/00523589.pdf (accessed accessed May 28, 2020). 
44. General Pharmaceutical Council. Tomorrow's pharmacy team: Future standards for the initial education and training of pharmacists, pharmacy technicians and pharmacy support staff. London: General Pharmaceutical Council; 2015.

45. Wright S. Scottish government invests $£ 2.85 \mathrm{~m}$ to expand experiential learning of student pharmacists to new settings. The Pharm J. March 5, 2019. Available at: https://www.pharmaceutical-journal.com/news-and-analysis/news-in-brief/scottishgovernment-invests-285m-to-expand-experiential-learning-of-student-pharmacists-to-newsettings/20206248.article?firstPass=false (accessed May 28, 2020). 